\title{
The association between experiencing homelessness in childhood or youth and adult housing stability in Housing First
}

\author{
Milad Parpouchi", Akm Moniruzzaman and Julian M. Somers
}

\begin{abstract}
Background: Researchers have pointed out the paucity of research investigating long-term consequences of experiencing homelessness in childhood or youth. Limited research has indicated that the experience of homelessness in childhood or youth is associated with adverse adjustment-related consequences in adulthood. Housing First (HF) has acknowledged effectiveness in improving housing outcomes among adults experiencing homelessness and living with serious mental illness, although some HF clients struggle with maintaining housing. The current study was conducted to examine whether the experience of homelessness in childhood or youth increases the odds of poorer housing stability following entry into high-fidelity HF among adults experiencing serious mental illness and who were formerly homeless.

Methods: Data were drawn from the active intervention arms of a HF randomized controlled trial in Metro Vancouver, Canada. Participants $(n=297)$ were referred to the study from service agencies serving adults experiencing homelessness and mental illness between October 2009 and June 2011. The Residential Time-Line Follow-Back Inventory was used to measure housing stability. Least absolute shrinkage and selection operator was used to estimate the association between first experiencing homelessness in childhood or youth and later housing stability as an adult in HF.
\end{abstract}

Results: Analyses indicated that homelessness in childhood or youth was negatively associated with experiencing housing stability as an adult in $\mathrm{HF}(\mathrm{aOR}=0.53 ; 95 \% \mathrm{Cl}=0.31-0.90)$.

Conclusions: Further supports are needed within HF to increase housing stability among adult clients who have experienced homelessness in childhood or youth. Asking clients about the age they first experienced homelessness may be of clinical utility upon enrollment in $\mathrm{HF}$ and may help identify support needs related to developmental experiences. Results further emphasize the importance of intervening earlier in life in childhood and youth before experiencing homelessness or before it becomes chronic. Findings also contribute to a limited knowledge base regarding the adverse long-term consequences of childhood and youth homelessness.

Trial registration: Current Controlled Trials: ISRCTN57595077 and ISRCTN66721740. Registered on October 9, 2012.

Keywords: Homelessness, Mental illness, Housing stability, Housing First, Canada

\footnotetext{
* Correspondence: spa16@sfu.ca

Somers Research Group, Faculty of Health Sciences, Simon Fraser University, Blusson Hall, Room 11300, 8888 University Drive, Burnaby, British Columbia V5A 156, Canada
}

\section{$\triangle B M C$}

(C) The Author(s). 2021 Open Access This article is licensed under a Creative Commons Attribution 4.0 International License, which permits use, sharing, adaptation, distribution and reproduction in any medium or format, as long as you give appropriate credit to the original author(s) and the source, provide a link to the Creative Commons licence, and indicate if changes were made. The images or other third party material in this article are included in the article's Creative Commons licence, unless indicated otherwise in a credit line to the material. If material is not included in the article's Creative Commons licence and your intended use is not permitted by statutory regulation or exceeds the permitted use, you will need to obtain permission directly from the copyright holder. To view a copy of this licence, visit http://creativecommons.org/licenses/by/4.0/ The Creative Commons Public Domain Dedication waiver (http://creativecommons.org/publicdomain/zero/1.0/) applies to the data made available in this article, unless otherwise stated in a credit line to the data. 


\section{Background}

Homelessness has become a public health crisis in North America. In Canada, it has been estimated that 235,000 people experience homelessness each year, with 35,000 people experiencing it each night. About 20\% are unaccompanied youth ages 13-24, equating to approximately 35,000-40,000 people [1]. A national point-intime homeless count in the U.S. found about 553,000 people experiencing homelessness in 2018, and nearly 7 $\%$ were unaccompanied youth under the age of 25, equating to approximately 36,000 people [2]. Moreover, over 1.35 million children enrolled in elementary and secondary public schools in the 2016-2017 school year were reported as homeless in the U.S. alone [3]. About 2.5 million children under the age of 18 are estimated to be experiencing homelessness on an annual basis in the U.S. [4].

Homelessness has increased since the 1980s in many Western countries, and demographic changes have accompanied this increase within the population $[1,5,6]$. As one example, in Canada, a greater proportion of people experiencing homelessness are youth than was the case prior to the 1980s [1]. Furthermore, families and children among people experiencing homelessness are increasing at the highest rate [7]. In the U.S., families with children now comprise one-third of people experiencing homelessness [2], and this figure has also grown since the 1980s [6].

Youth experiencing homelessness may develop skills necessary to live on the streets [8], but may not have yet had opportunities to develop the life skills necessary for living independently [8, 9]. Additionally, researchers have hypothesized that experiencing homelessness earlier in life, during sensitive developmental years, may have more harmful consequences later in life [10]. Kilmer and colleagues have argued that the stressors involved in the experience of homelessness during childhood may increase "the likelihood that youngsters will evidence difficulties as they move along their adjustment trajectories" [11] p. 391. Similar arguments have been made regarding development for those experiencing homelessness in youth [12].

Numerous studies have found that homelessness during childhood or youth is associated with a myriad of health and social problems, including, infectious disease, chronic physical health conditions, poor nutrition, dental disease, mental illness, substance abuse, injury, mortality, poorer cognitive functioning and academic performance, behavioral health risks, and violence [12-14]. A systematic review of studies using "full psychiatric diagnostic interview [s]" found the prevalence of psychiatric disorders among youth experiencing homelessness to be between 48 and $98 \%$ ([15], p. e3). Moreover, the experience of homelessness as a very young child may also be associated with adverse consequences, such as developmental delays. For example, one study found that infants and children aged 2 months to 6 years experiencing homelessness had developmental scores at levels significantly poorer than the general population, with the most pronounced differences in the domains of language and communication [16].

Findings from some longitudinal studies suggest that experiencing homelessness earlier in life may be independently and significantly associated with adverse consequences later in life. For example, one prospective study among participants aged 18-26 found that the experience of homelessness before the age of 26 was independently and significantly associated with an increased likelihood of committing a violent or property crime later in adulthood [17]. Similarly, using panel data among a representative sample of people in Australia at least 15 years of age who had experienced homelessness or were at risk, Cobb-Clark and Zhu [10] found that the experience of homelessness first in childhood ( $\leq 15$ years of age) among men aged 21-54 years in the study was significantly associated with a decreased likelihood of employment in adulthood in their adjusted model, compared to the men who had first experienced homelessness later in their life. When potential mediating variables were considered, there was still a direct effect. Using eight-year follow-up data from the National Longitudinal Survey of Youth-Child Study, Stablein and Appleton [18] compared the health of adolescents and young adults who were formerly homeless (ages 15-25) to those who had not experienced homelessness. They found that the experience of homelessness (occurring any time between 2000 and 2006) was significantly associated with having an incident case of asthma, a health-limiting condition, and developing poorer self-rated health following homelessness at the final follow-up (2008). The relationship between homelessness and asthma and having a health-limiting condition was partly mediated by other variables, but the relationship with self-rated health remained independent. The experience of homelessness was also independently and significantly associated with lower education attainment, an increased risk of depressive symptoms, and alcohol and substance abuse following homelessness. A crosssectional study conducted in Canada similarly found that the earlier the age of first experiencing homelessness, the higher the likelihood of being in high psychological distress among a large sample of youth accessing services for people experiencing homelessness [19].

In light of the above longitudinal studies reporting adverse long-term consequences of homelessness among children and youth, it may be the case that once an 
adult, people may have difficulty adjusting to housing and support interventions. One such intervention may be Housing First (HF).

HF is a supported housing model that brings together permanent housing and health and social services for people experiencing homelessness and serious mental illness $[20,21]$. Based on the psychosocial rehabilitation model (also called psychiatric rehabilitation) [22-24], clients of HF are provided choice and can decide what, if any, services to engage in while in the program (e.g., mental health treatment) [25]. Such choice is also extended to substance use, as there are no programmatic requirements regarding abstinence [20].

Since its establishment in New York City [20], HF has been implemented in many parts of the globe, including, but not limited to, Canada [26], Australia [27], and Europe [28]. Systematic reviews have consistently found HF to be associated with increased housing stability outcomes [29-32]. In a recent review of tenancy sustainment following homelessness, Boland et al. [31], concluded "that Housing First is the most promising intervention" [p. e6].

What is less often discussed in the literature is the proportion of people for whom HF does not help to maintain housing stability. Volk et al. [33] noticed a trend in the literature; about $15-20 \%$ of participants in HF studies exhibit housing instability. A few studies have quantitatively investigated factors associated with housing instability, retention, or relocations within HF [3338 ], however, to our knowledge, no studies have reported the association between first experiencing homelessness in childhood or youth and subsequent housing stability in adulthood within HF. Adair et al. [38] included the age of first experiencing homelessness as a predictor in their modelling approach, but results were not reported for this specific variable. More broadly, other researchers have pointed out the paucity of research investigating long-term consequences of experiencing homelessness in childhood or youth [10].

The objective of the current study was to examine the association between having first experienced homelessness in childhood or youth and housing stability following the implementation of high-fidelity HF among adults experiencing homelessness or precarious housing and living with serious mental illness. We hypothesized that the experience of homelessness in childhood or youth would be significantly and independently associated with poorer housing stability after receiving $\mathrm{HF}$ as an adult. Such research is important to: 1) contribute to the understanding of risk for poorer housing stability after receiving HF 2) improve policies and practices related to the intervention, and 3) add to the limited literature regarding long-term consequences of childhood and youth homelessness.

\section{Methods}

\section{Participants and sampling}

The present study is based on a larger experimental investigation called Vancouver At Home (VAH), which included two pragmatic randomized controlled field trials involving two years of follow-up (Current Controlled Trials: ISRCTN57595077 and ISRCTN66721740). The trials examined HF in congregate and scattered-site configurations among adults experiencing homelessness or precarious housing and living with serious mental illness $(n=497)$ in Metro Vancouver, British Columbia, Canada. Interventions were compared to treatment as usual (TAU). The protocol for VAH has been published [39].

Participants were referred to the study from service agencies serving adults experiencing homelessness and mental illness (e.g., homeless shelters) in Metro Vancouver, Canada between October 2009 and June 2011. Study eligibility included: being a Canadian citizen, at least 19 years of age, absolutely homeless or precariously housed, and having a serious mental illness (assessed by the Mini International Neuropsychiatric Interview [MINI]) [40]. VAH considered participants with "no fixed place to sleep or live for more than 7 nights and little likelihood of obtaining accommodation in the coming month" as absolutely homeless [39] p. 3. Participants "currently residing in marginal accommodation, such as a SRO [single-room occupancy] hotel, and having two or more episodes of [absolute] homelessness (as defined above) during the past 12 months" were considered precariously housed [39] p. 3. Written informed consent was provided by participants.

Once enrolled in the study, a range of intervieweradministered questionnaires were used to elicit information from participants at baseline, including, but not limited to, socio-demographics, service use, mental disorders and symptoms, community functioning, physical comorbidities, and substance use. Data collected during the baseline interview were also used to determine participant support need levels. A comprehensive assessment algorithm was used to differentiate participants with "high needs" from "moderate needs". Criteria determining participants with high needs included the presence of a psychotic disorder or bipolar disorder (according to the MINI) [40], receiving a score of $\leq 62$ on the Multnomah Community Ability Scale [41], and one of the following: having a history of arrest or incarceration in the past six months (using the Demographics, Service \& Housing History [DSHH] questionnaire; see Additional file 1), two or more psychiatric hospitalizations in one of the past 5 years (using the Screener questionnaire; see Additional file 2), or substance dependence (according to the MINI) [40]. All other participants were considered as having moderate needs. 
Additional information about $\mathrm{VAH}$, such as sampling and questionnaires used, have been published [see 39]. The study underwent ethics review and was approved by the Research Ethics Board of Simon Fraser University. The study was also conducted as per relevant guidelines and regulations.

\section{Interventions}

The two VAH randomized controlled trials were differentiated based on participant need levels (i.e., moderate vs. high needs). The randomized controlled trial for those with moderate needs randomly allocated participants to either scattered-site HF with intensive case management (HF-ICM) or TAU (comprised of existing services in the community). The randomized controlled trial for those with high needs randomly allocated participants to scattered-site HF with assertive community treatment (HF-ACT), congregate HF with on-site support (CONG), or TAU. A description of each HF intervention follows.

The HF-ICM intervention included a private rental apartment of the participant's choice in Metro Vancouver combined with intensive case management whereby case managers helped participants access existing community services and were available $12 \mathrm{~h}$ a day. HF-ACT included the same housing as HF-ICM, but the support service component included a multi-disciplinary health and social service provider team located in the community and available 24/7. The CONG intervention involved a single building all occupied by study participants. Participants were provided an independent room and bathroom, but other spaces were shared with tenants (e.g., kitchen). The support component of CONG involved on-site health and social services available 24/7. Moreover, a range of recreational and volunteer activities were provided as part of the intervention. Somers et al. [39] have published additional information on interventions and randomization procedures. We only included participants randomized to intervention arms (i.e., HF-ICM, HF-ACT, or CONG) in the current study.

\section{Variables of interest}

The main outcome was housing stability and was measured using the Residential Time-Line Follow-Back Inventory every three months [42]. Validity of the Residential Time-Line Follow-Back Inventory has been demonstrated among people experiencing homelessness and serious mental illness, with administrative data from agencies providing housing and support used as the reference comparison [42]. Stable housing was defined as having tenancy rights or living in one's own apartment/ room/house/family for an expected time of at least 6 months. Unstable housing was defined as living on the streets or in temporary accommodations, including, but not limited to shelters, hospitals, and crisis units [43]. For the present study, we operationalized housing stability as participants spending $\geq 90 \%$ of days in stable housing during the 2-year follow-up period. Participants spending $<90 \%$ of days in stable housing were considered unstably housed. Researchers have argued that definitions of housing stability in the literature are widely inconsistent e.g., [33, 42]. The ideal purpose of HF is to eliminate homelessness and facilitate stable housing, however, as Pearson et al. [34] argue, "housing stability in Housing First programs is an iterative process [and] temporary departures from housing are not uncommon ... These episodic departures are part of a stabilizing strategy to ensure that clients maintain their engagement in housing and treatment" [p. 415]. Given that HF clients are among the most vulnerable and marginalized of people experiencing homelessness and that temporary exits from the program may be part of the journey to recovery, we decided on $90 \%$ as the stable housing cut-off.

The primary independent variable was age of first experiencing homelessness and was asked during the study's baseline interview using the DSHH (see Additional file 1 for this questionnaire). Youth have been commonly defined as up to the age of 24 or 25 e.g., [13, 44-46]. The United Nations [45] defines youth as 1524 years of age and children as below this age $(<14$ years of age). Because we were interested in the experience of homelessness in childhood or youth, we operationalized our primary independent variable as age of first experiencing homelessness and dichotomized it as $<25$ years vs. $\geq 25$ years.

Intervention type and other relevant variables at baseline were included per prior literature as control covariates. Apart from the type of HF intervention variable (HF-ICM, HF-ACT, CONG), socio-demographic variables were asked from the DSHH and included gender (woman, man), ethnicity (Indigenous, White, Other), education (less than high school, high school or higher), and marital status (single and never married, other). Age at randomization ( $<25$ years, 25-44 years, $>44$ years) was asked from the Screener (see Additional file 2 for this questionnaire). Lifetime duration of homelessness ( $\leq$ 36 months, $>36$ months) and longest episode of homelessness ( $\leq 12$ months, $>12$ months) were asked from the DSHH, while housing status at enrollment (absolutely homeless, precariously housed) was asked from the Screener. Criminal justice variables were asked from the DSHH and included the following two, occurring anytime in the 6 months preceding baseline: 1) having been arrested $(>1)$, imprisoned $(\geq 1)$, on probation, or received a community sanction (yes/no) and 2 ) having spent at least one night in jail (yes/no). Mental illness variables included mental health symptom severity (Colorado 
Symptom Index score; higher scores indicate greater symptom severity) [47], the less severe cluster of mental disorders (yes/no; includes at least one of: major depressive episode, panic disorder, or post-traumatic stress disorder according to the MINI) [40], and the severe cluster of mental disorders (yes/no; includes at least one of: psychotic disorder, mood disorder with psychotic features, or manic or hypomanic episode according to the MINI) [40]. Learning disability variables included perceiving having had a learning disability in childhood (yes/no) and having been told of having a learning disability in childhood (yes/no) and were asked from the Screener. Community functioning was determined by the Multnomah Community Ability Scale score (interviewer-rated; higher scores indicate greater community functioning) [41]. Substance use behaviours and income related to sex work in the month preceding baseline were asked from the Maudsley Addiction Profile [48] and included use of alcohol (yes/no), heroin (yes/no), illicit methadone (yes/no), benzodiazepines (yes/no), cocaine (yes/no), crack (yes/no), amphetamine (yes/no), cannabis (yes/no), injection of drugs (yes/no), daily substance use (yes/no; including alcohol), daily drug use (yes/no; excluding alcohol), daily hard drug use (yes/no; excluding alcohol and cannabis), and sex work-related income (yes/no). Money spent on alcohol (yes/no; in Canadian dollars) and money spent on drugs (yes/no; in Canadian dollars) were asked from the Global Assessment of Individual Need (Substance Problem Scale) [49].

Three additional control covariates were included but were not collected at study baseline. Experiences of family separation and foster care were asked at the 12month follow-up interview from the Vancouver Foster Care questionnaire used in a previous VAH study [50]. The two variables included having lived away from parents for any reason under the age of 18 (yes/no) and having ever been in foster care (yes/no). Information related to adverse childhood experiences was asked from the Adverse Childhood Experiences questionnaire [51] at the 18-month follow-up interview (calculated as a total score up to 10 corresponding to the number of categories of adverse experiences reported). Information related to all questionnaires administered in VAH have been published [39]. All VAH questionnaires were interviewer-administered in person.

\section{Statistical analysis}

Means and standard deviations were presented for continuous variables, and percentages were presented for categorical variables. Least absolute shrinkage and selection operator (LASSO) was used to model the primary independent variable of interest (i.e., age of first experiencing homelessness) and housing stability. LASSO is a regression analysis method which is used in selecting and fitting variables for a statistical model with a large set of potential covariates [52]. It uses a modern data driven method that selects only a subset of the provided variables for the model and tests them in other datasets in order to improve the prediction accuracy and interpretability of regression models. Moreover, LASSO can be used to make inference about the variable of interest in the presence of many potential control covariates [53, 54]. Among LASSO, the cross-fit partialing-out method was specified. This method, which is also known as Double Machine Learning, has a better finite sample property and is more robust, due to the cross-fit nature (coefficients are obtained from one sample and used in another, and this procedure is repeated several times) and split sample technique [54, 55]. In the current analysis, the effect (odds ratio) of the age in which participants first experienced homelessness on housing stability was estimated using binary logistic regression. In the LASSO model, age of first experiencing homelessness was used as the primary independent variable of interest and all other variables (e.g., age, gender, ethnicity, etc.) and their interaction terms were used as controlling covariates. The two variables related to family separation (i.e., having lived away from parents for any reason under the age of 18 and having been in foster care) and the variable pertaining to adverse childhood experiences were not included as control covariates in the primary LASSO multivariable model because data for these variables were collected at later follow-up interviews than the other independent variables, which were collected at baseline. It was also expected that the inclusion of these variables would result in a substantially reduced sample size since they were asked later on in the study. However, in order to control for these variables, two separate LASSO models were conducted as sensitivity analyses, one of which included the two family separation-related variables in addition to the other control covariates originally included in the primary multivariable model. The second sensitivity analysis included the adverse childhood experiences variable in addition to the other control covariates originally included in the primary multivariable model. $P$-values less than 0.05 were considered significant. Missing values were low (< $1.5 \%$ ) - with the exception of the use of cannabis variable (this variable was added after study recruitment had begun; 9.4\% missing) - and were replaced by median values for continuous variables and by largest group for categorical variables. For the outcome, housing stability, the last observation was carried forward in the event of missing data. Stata 16 [56] was used to conduct these analyses.

The follow-up period included the date of randomization until the last available follow-up interview. Follow-up rates are shown in Somers et al. [39]. 


\section{Results}

Overall, 497 participants were enrolled into VAH. Of these participants, $297(60 \%)$ were randomized to HF intervention arms, including 100 to HF-ICM, 90 to HF$\mathrm{ACT}$, and 107 to CONG. Figure 1 presents the flow of participants. About $44 \%$ of participants reported first experiencing homelessness before the age of 25 . Results for additional characteristics of participants are listed in Table 1.

Housing stability outcomes are listed in Table 2. Overall housing stability was $0.73(\mathrm{SD}=0.27)$ and was similar by $\mathrm{HF}$ intervention, including $0.72(\mathrm{SD}=0.30)$ for HF-
ICM, 0.74 $(\mathrm{SD}=0.25)$ for HF-ACT, and 0.74 $(\mathrm{SD}=0.26)$ for CONG. About $40 \%$ of participants spent $\geq 90 \%$ of days in stable housing during the two years of follow-up, including $44 \%$ of participants in HF-ICM, about 36\% in HF-ACT, and about $39 \%$ in CONG.

Table 3 presents results from the primary unadjusted and adjusted LASSO analyses. Prior to adjustment with control variables, participants who experienced homelessness $<25$ years of age were half as likely to have spent $\geq 90 \%$ of days in stable housing ( $\mathrm{uOR}=0.50$; $95 \%$ $\mathrm{CI}=0.31-0.81)$. This result remained statistically

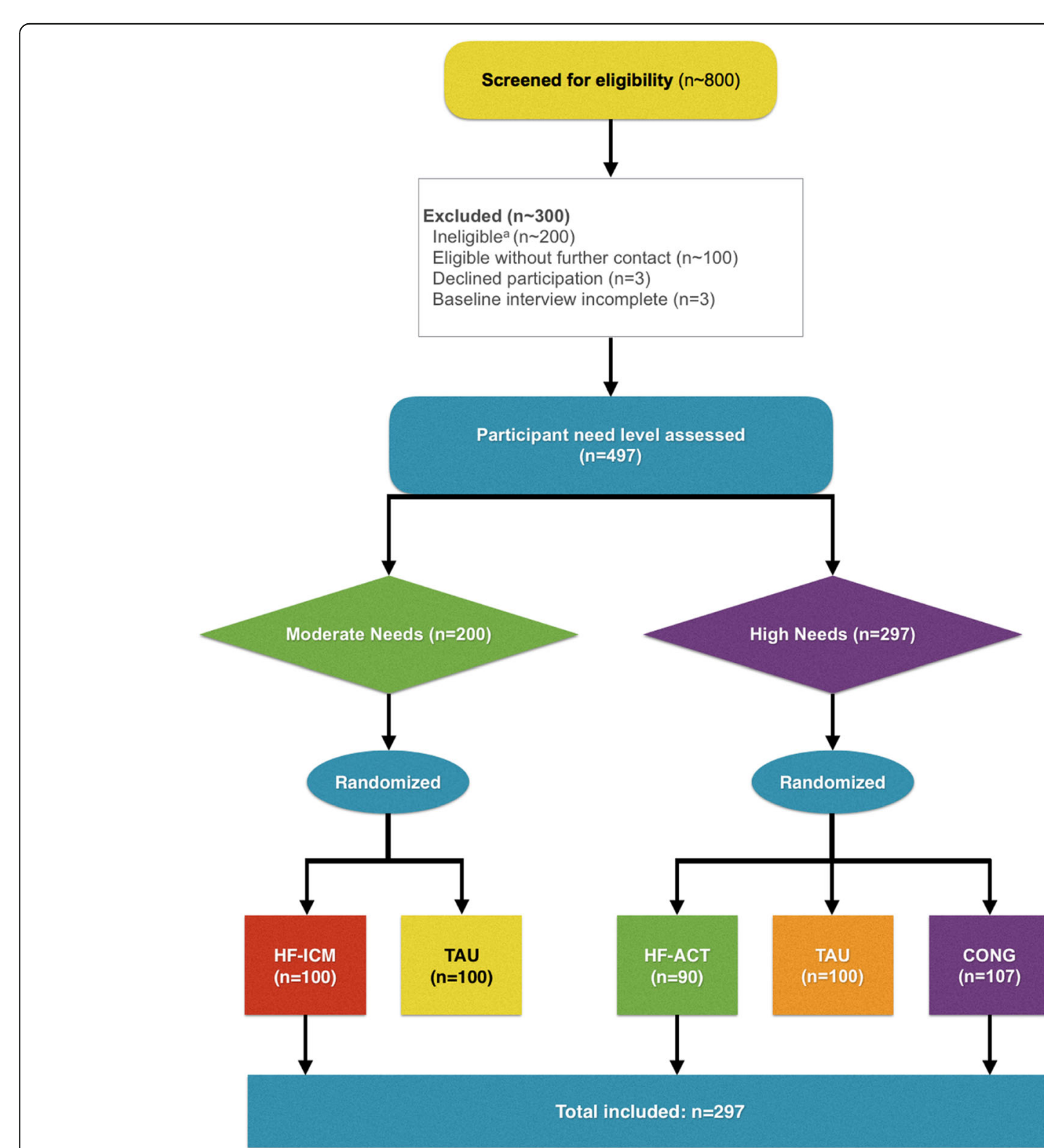

Fig. 1 Flow of participants. Includes about 100 participants ineligible after telephone screening, and 94 participants after in-person screening. Abbreviations: HF-ICM = Housing First with intensive case management; TAU = Treatment as usual; HF-ACT = Housing First with assertive community treatment; $\mathrm{CONG}=$ Congregate Housing First with on-site support. 
Table 1 Characteristics of Vancouver At Home participants randomized to Housing First $(n=297)$

Variable

Socio-demographics

Age at randomization

$$
<25 \text { years }
$$$$
\text { 25-44 years }
$$$$
>44 \text { years }
$$

Gender

Woman

Man

Ethnicity

Indigenous

White

Other

Education

Less than high school

High school or higher

Marital Status

Single (never married)

Other

\section{Homelessness}

Age of first homeless

$$
<25 \text { years }
$$$$
\geq 25 \text { years }
$$

Lifetime duration of homelessness

$$
\leq 36 \text { months }
$$$$
>36 \text { months }
$$

Longest episode of homelessness

$$
\leq 12 \text { months }
$$$$
>12 \text { months }
$$

Housing status (at enrollment)

$$
\text { Absolutely homeless }
$$

Precariously housed

\section{Criminal justice (past 6 months)}

Arrested $(>1)$, imprisoned $(\geq 1)$, on probation, or received community sanction

$$
\text { No }
$$

Yes

Spent at least one night in jail

No

Yes

Mental illness, learning disability, and community functioning

Mental health symptom severity (Colorado Symptom Index score)

$$
\text { Mean (SD) }
$$

Less severe cluster of mental disorders

No

147 (49.5)

Yes

$150(50.5)$ 
Table 1 Characteristics of Vancouver At Home participants randomized to Housing First $(n=297)$ (Continued)

Variable

Severe cluster of mental disorders

No

Yes

Learning disability in childhood (you perceived)

No

Yes

Learning disability in childhood (someone told you)

No

Yes

Community functioning (Multnomah Community Ability Scale score)

Mean (SD)

\section{Family separation and adverse childhood experiences}

Lived away from parents for any reason under the age of 18

No

$110(40.1)$

Yes

$164(59.9)$

Ever placed in foster care ${ }^{2}$

No

$190(69.3)$

Yes

84 (30.7)

Adverse childhood experiences (ACE) ${ }^{3}$

Mean (SD)

\section{Substance use (past month)}

Use of alcohol

No

$164(55.6)$

Yes

$131(44.4)$

Use of heroin

No

$240(81.4)$

Yes

55 (18.6)

Use of illicit methadone

No

$283(95.9)$

Yes

$12(4.1)$

Use of benzodiazepines

No

Yes

$268(91.2)$

$26(8.8)$

Use of cocaine

No

$245(83.1)$

Yes

50 (16.9)

Use of crack

No

$197(66.8)$

Yes

98 (33.2)

Use of amphetamine

No

254 (86.7)

Yes

39 (13.3)

Use of cannabis

No 
Table 1 Characteristics of Vancouver At Home participants randomized to Housing First $(n=297)$ (Continued)

\begin{tabular}{|c|c|}
\hline Variable & $n(\%) /$ mean (SD) \\
\hline Yes & $121(45.0)$ \\
\hline \multicolumn{2}{|l|}{ Injected drugs } \\
\hline No & 239 (81.6) \\
\hline Yes & $54(18.4)$ \\
\hline \multicolumn{2}{|l|}{ Daily substance use (including alcohol) } \\
\hline No & $211(71.5)$ \\
\hline Yes & $84(28.5)$ \\
\hline \multicolumn{2}{|l|}{ Daily drug use (excluding alcohol) } \\
\hline No & $218(73.9)$ \\
\hline Yes & $77(26.1)$ \\
\hline \multicolumn{2}{|l|}{ Daily hard drug use (excluding alcohol \& cannabis) } \\
\hline No & $251(85.1)$ \\
\hline Yes & $44(14.9)$ \\
\hline \multicolumn{2}{|l|}{ Money spent on alcohol (CAD) } \\
\hline Mean (SD) & $60.0(164.5)$ \\
\hline \multicolumn{2}{|l|}{ Money spent on drugs (CAD) } \\
\hline Mean (SD) & $331.3(852.9)$ \\
\hline \multicolumn{2}{|l|}{ Other } \\
\hline \multicolumn{2}{|l|}{ Sex work-related income (past month) } \\
\hline No & $282(94.9)$ \\
\hline Yes & $15(5.1)$ \\
\hline \multicolumn{2}{|l|}{ Type of Housing First intervention } \\
\hline Housing First with intensive case management & $100(33.7)$ \\
\hline Housing First with assertive community treatment & $90(30.3)$ \\
\hline Congregate housing with on-site support & $107(36.0)$ \\
\hline
\end{tabular}

${ }^{1}$ The variable "Lived away from parents for any reason under the age of 18" was asked at the 12-month follow-up interview, with information available for 274 participants

2 The variable "Ever placed in foster care" was asked at the 12-month follow-up interview, with information available for 274 participants

${ }^{3}$ The variable "Adverse childhood experiences" was asked at the 18-month follow-up interview, with information available for 229 participants

significant following adjustment with control variables $(\mathrm{aOR}=0.53 ; 95 \% \mathrm{CI}=0.31-0.90)$.

Table 4 presents results from both sensitivity analyses. In the first sensitivity analysis, two family separationrelated variables (having lived away from parents for any reason under the age of 18 and having ever been in foster care) were added as control covariates to the ones that had been included in the primary multivariable model. The sample size was reduced $(n=274)$, and the experience of homelessness < 25 years of age remained significantly and negatively associated with housing stability both in the unadjusted $(\mathrm{OR}=0.51 ; 95 \% \mathrm{CI}=0.31$ 0.85 ) and adjusted models ( $\mathrm{aOR}=0.54 ; 95 \%$ CI: $0.31-$ 0.95).

In the second sensitivity analysis, the adverse childhood experiences total score was added as a control

Table 2 Housing stability among Vancouver At Home participants by Housing First intervention $(n=297)$

\begin{tabular}{lllll}
\hline & Overall & HF-ICM $(\boldsymbol{n}=\mathbf{1 0 0})$ & HF-ACT $(\boldsymbol{n}=\mathbf{9 0})$ & CONG $(\boldsymbol{n}=\mathbf{1 0 7})$ \\
\hline $\begin{array}{l}\text { Housing stability } \\
\text { Mean (SD) }\end{array}$ & $0.73(0.27)$ & $0.72(0.30)$ & $0.74(0.25)$ & $0.74(0.26)$ \\
$\begin{array}{l}\text { Housing stability, } n(\%) \\
\quad<90 \% \text { of days }\end{array}$ & $179(60.3)$ & $56(56.0)$ & $58(64.4)$ & $65(60.8)$ \\
$\geq 90 \%$ of days & $118(39.7)$ & $44(44.0)$ & $32(35.6)$ & $42(39.3)$ \\
\hline
\end{tabular}

Abbreviations: HF-ICM Housing First with intensive case management, HF-ACT Housing First with assertive community treatment, CONG Congregate Housing First with on-site support 
Table 3 Least absolute shrinkage and selection operator analyses to estimate the association between first experiencing homelessness in childhood or youth ( $<25$ years) and housing stability $(\geq 90 \%)$ among Vancouver At Home participants randomized to Housing First $(n=297)$

\begin{tabular}{|c|c|c|c|c|}
\hline & Unadjusted Odds Ratio $(95 \% \mathrm{Cl})$ & $P$ value & Adjusted Odds Ratio (95\% Cl) & $P$ value \\
\hline \multicolumn{5}{|c|}{ Age of first homeless } \\
\hline$<25$ years & $0.50(0.31,0.81)$ & 0.005 & $0.53(0.31,0.90)$ & 0.020 \\
\hline$\geq 25$ years & Reference & & Reference & \\
\hline
\end{tabular}

covariate to the ones that had been included in the primary multivariable model. This reduced the sample size $(n=229)$ and resulted in a slightly attenuated effect size $(\mathrm{OR}=0.60 ; 95 \% \mathrm{CI}: 0.33-1.11)$ compared to the primary multivariable model. The $p$-value also became marginally significant $(p=0.103)$.

\section{Discussion}

Consistent with our hypothesis, the experience of homelessness in childhood or youth was significantly and independently associated with lower odds of experiencing housing stability in HF. More specifically, compared to participants who had first experienced homelessness at age 25 or older, participants who had first experienced homelessness under the age of 25 had half the odds of experiencing housing stability as an adult in HF over 24 months.

This finding adds to limited research demonstrating long-term consequences of homelessness for children and youths $[10,17]$ and underscores the additional support needs of participants in HF. It has been suggested that exposure to and integration into "homeless subculture" [57] p. 578 in childhood or youth via street survival skills, and friendships developed with other people experiencing homelessness and the subsequent "camaraderie" make it more difficult to exit homelessness [57] p. 576. As Johnson and Chamberlain [57] argue, "without a meaningful role to perform and new social networks to engage with, some people find it difficult to disengage from the homeless subculture when it is their primary social network" [p. 578]. These findings are supported by qualitative analyses of VAH outlining lack of meaningful activity and work, boredom, and social isolation following randomization to $\mathrm{HF}$, albeit these data were not broken down by age of first experiencing homelessness [58].

Additionally, studies from the psychosocial rehabilitation and occupational therapy literature dating back as far as the 1980s $[8,59]$ outlined a range of barriers youth experiencing homelessness faced to independent living, including, but not limited to, unemployment and lack of employment skills, educational deficits, mental health problems, problematic substance use, inadequate social support, and family problems [59]. Helfrich et al. [8] further argue that youth experiencing homelessness "have limited opportunities to develop life skills that promote mainstream roles such as that of student, family member or worker" [p. 191]. These same skill deficits may persist into adulthood without adequate supports. Participants who had experienced homelessness in childhood or youth may have had a more difficult time developing these skills while in VAH HF interventions. Findings of the present study warrant replication and may expose an important area of further research examining the consequences of developmental experiences as they contribute to housing stability.

Research is also needed to determine what modifications and additional support services are needed within

Table 4 Sensitivity analyses - least absolute shrinkage and selection operator analyses to estimate the association between first experiencing homelessness in childhood or youth (<25 years) and housing stability $(\geq 90 \%)$ among Vancouver At Home participants randomized to Housing First

\begin{tabular}{|c|c|c|c|c|c|}
\hline Control Covariates Added & $\begin{array}{l}\text { Primary Independent } \\
\text { Variable }\end{array}$ & $\begin{array}{l}\text { Unadjusted Odds Ratio } \\
(95 \% \mathrm{Cl})\end{array}$ & $\begin{array}{l}P \\
\text { value }\end{array}$ & $\begin{array}{l}\text { Adjusted Odds Ratio } \\
(95 \% \mathrm{Cl})\end{array}$ & $\begin{array}{l}P \\
\text { value }\end{array}$ \\
\hline \multirow[t]{3}{*}{ Family separation $(n=274)^{1}$} & Age of first homeless & & & & \\
\hline & $<25$ years & $0.51(0.31,0.85)$ & 0.009 & $0.54(0.31,0.95)$ & 0.032 \\
\hline & $\geq 25$ years & Reference & & Reference & \\
\hline \multirow{3}{*}{$\begin{array}{l}\text { Adverse childhood experiences score } \\
(n=229)^{2}\end{array}$} & Age of first homeless & & & & \\
\hline & $<25$ years & $0.55(0.32,0.96)$ & 0.035 & $0.60(0.33,1.11)$ & 0.103 \\
\hline & $\geq 25$ years & Reference & & Reference & \\
\hline
\end{tabular}

${ }^{1}$ In addition to control covariates included in the primary LASSO multivariable model, two family separation variables were added: 1) "Lived away from parents for any reason under the age of 18" (yes/no) and 2) "Ever placed in foster care" (yes/no)

${ }^{2}$ In addition to control covariates included in the primary LASSO multivariable model, the following variable was added: "Adverse childhood experiences" (score) 
HF interventions to increase housing stability for adults who first experienced homelessness in childhood or youth, but two additional implications can also be drawn from the present study: 1) our analyses suggest that gathering information about age of first experiencing homelessness may be of clinical utility upon enrollment in HF, and may help identify support needs related to developmental challenges and experiences, and 2) it is vital to implement housing and support interventions targeting children and youth with or without family members before they become homeless or immediately after becoming so. Other researchers have called for HF as a potential solution among youth experiencing homelessness [60].

A multisite, experimental investigation, which included VAH as one of its sites, previously found HF to be associated with significantly improved housing stability compared to TAU among youth ages 18-24 living with serious mental illness. Results were similar when compared to those older than 24 years of age. However, secondary and exploratory outcomes of the same study were not as promising, with HF even being associated with significantly decreased rates of employment relative to TAU [46]. Differences in needs between youth and adults have led to adaptations of HF specifically for youth $[61,62]$. However, there is a paucity of research examining HF among youth experiencing homelessness [62], and existing research on youth experiencing both homelessness and serious mental illness has found that some do not prefer to live independently due to isolation, continued substance use challenges, and potential cultural-related factors, such as leaving one's existing social circle [9]. Further research is needed to clarify modifications to HF that best support housing stability for youth experiencing homelessness.

There also exists extremely limited research in the area of housing and support interventions for children in families experiencing homelessness. Limited research suggests HF, permanent supportive housing, and housing subsidies or affordable housing are effective in improving housing status [63-65], but reaching housing stability in the long-term has been identified as an unsolved problem [64], with further investigation urgently needed [63-65]. One large multisite study involving 3 y of follow-up comprehensively studied the effects of random assignment to long-term rent subsidies, short-term rent subsidies, and transitional housing combined with support services all compared to TAU among families experiencing homelessness in the U.S. Findings strongly favoured the long-term rent subsidy intervention compared to TAU, with significantly reduced homelessness, increased housing stability, and a variety of improved outcomes among children, including, but not limited to, a significantly reduced percentage of families with $\geq 1$ child separated in the past 6 months at 20 months of follow-up, fewer school absences at 20 months of followup, reduced behavioral problems at 37 months of followup, and increased food security at 20 and 37 months of follow-up [66].

Beyond HF, other policies and services that address childhood and youth homelessness should be implemented at the earliest possible in order to prevent chronic adverse health and social consequences [67]. As Gaetz et al. [67] outline, these efforts should target primary prevention (e.g., affordable and social housing availability, services to prevent adverse childhood experiences in families, and supports while transitioning out of foster and other institutional care), secondary prevention (e.g., emergency rental funds [68]), and tertiary prevention (e.g. housing and health and social services provided to children, youth, and families experiencing homelessness).

The present study involved several limitations. Although results were similar when the two family separation-related variables were added to the primary multivariable model in the first sensitivity analysis, the same was not the case for the second sensitivity analysis. Specifically, when the adverse childhood experiences variable was added to the primary adjusted model in the second sensitivity analysis, the relationship between first experiencing homelessness in childhood or youth and housing stability became marginally significant, with the same directional relationship as observed in the initial model. However, this was likely due to the considerably reduced sample size $(n=229)$, which also resulted in a wider $95 \%$ confidence interval. Additional studies with larger sample sizes are needed to confirm results of the present analyses. It is also important for future research to examine and identify mediators of the relationship between first experiencing homelessness in childhood or youth and poorer housing stability as an adult in Housing First. Another limitation involved insufficient statistical power to include transgender and transsexual as separate variable levels, as one participant self-identified as transgender and another as transsexual. With the exception of the Multnomah Community Ability Scale [41], all variables were self-reported and may have been influenced by social desirability and recall bias. However, previous analyses have demonstrated validity of selfreport from participants of VAH [69]. Additionally, follow-up was limited to two years. Longer follow-up is needed to assess the stability of the differences we observed. Lastly, probability sampling was not employed in $\mathrm{VAH}$, limiting generalizability.

\section{Conclusion}

To our knowledge, no studies have investigated the effect of experiencing homelessness in childhood or youth 
on later housing stability as an adult in HF, and hence, the present study is the first of its kind. We found that participants who had first experienced homelessness in their childhood or youth had about half the odds of experiencing housing stability within HF as defined by spending at least $90 \%$ of days in stable housing. This association was both significant and independent. Our findings have implications for service delivery in HF. They also emphasize the importance of intervening earlier in life in childhood and youth before experiencing homelessness and before it becomes chronic, potentially resulting in poorer health and social outcomes. Future research should investigate how best to support adults experiencing housing instability within HF, and how to intervene to best support the housing and related health and social needs of children and youth experiencing homelessness.

\section{Abbreviations}

HF: Housing First; VAH: Vancouver At Home; TAU: Treatment as usual; MINI: Mini International Neuropsychiatric Interview; DSHH: Demographics, Service \& Housing History; HF-ICM: Housing First with intensive case management; HF-ACT: Housing First with assertive community treatment; CONG: Congregate Housing First with on-site support; LASSO: Least absolute shrinkage and selection operator

\section{Supplementary Information}

The online version contains supplementary material available at https://doi. org/10.1186/s12888-021-03142-0.

\section{Additional file 1:. Demographics, Service \& Housing History} questionnaire; description of data: provides details of the questionnaire and lists its items.

Additional file 2:. Screener questionnaire; description of data: provides details of the questionnaire and lists its items.

\section{Acknowledgements}

We are grateful for the invaluable contribution of the participants, service providers, and research team.

\section{Authors' contributions}

All authors contributed to the conception and design of the study, as well as data collection. AM led the statistical analysis. All authors contributed to data analysis and interpretation. The manuscript was drafted by MP and edited and commented on by AM and JMS. All authors read and approved the final manuscript.

\section{Authors' information}

Not applicable

\section{Funding}

Milad Parpouchi is a 2017 Pierre Elliott Trudeau Foundation Scholar. He is also funded by the Canadian Institutes of Health Research (Funding Reference Number: GSD-146191). Vancouver At Home was funded by the Mental Health Commission of Canada (Grant Number: 2009 s0124). The study funder (Mental Health Commission of Canada) required an experimental design but had no role in the collection, analysis or interpretation of the data, writing of the manuscript, nor the decision to submit the manuscript for publication.

\section{Availability of data and materials}

The datasets used and/or analyzed during the current study are available from the third author (JMS) on reasonable request at jsomers@sfu.ca.

\section{Declarations}

\section{Ethics approval and consent to participate}

The Study underwent ethics review and was approved by the Research Ethics Board of Simon Fraser University. All participants of Vancouver At Home provided written informed consent. The Study was conducted as per relevant guidelines and regulations.

\section{Consent for publication}

Not applicable.

\section{Competing interests}

The authors declare that they have no competing interests.

Received: 24 October 2020 Accepted: 25 February 2021

Published online: 08 March 2021

\section{References}

1. Gaetz S, Dej E, Richter T, Redman M. The state of homelessness in Canada 2016. Toronto: Canadian Observatory on Homelessness Press; 2016. https:// www.homelesshub.ca/sites/default/files/attachments/SOHC16_final_200ct2 016.pdf. Accessed 24 Oct 2018.

2. Henry M, Mahathey A, Morrill T, Robinson A, Shivji A, Watt R, et al. The 2018 Annual Homeless Assessment Report (AHAR) to Congress, Part 1: point-intime estimates of homelessness. Office of Community Planning and development, The U.S. Department of Housing and Urban Development. 2018. https://www.huduser.gov/portal/sites/default/files/pdf/2018-AHAR-Pa rt-1.pdf. Accessed 5 Dec 2019.

3. National Center for Homeless Education. Federal data summary: school years 2014-15 to 2016-2017. National Center for Homeless Education 2019. https://nche.ed.gov/wp-content/uploads/2019/02/Federal-Data-SummarySY-14.15-to-16.17-Final-Published-2.12.19.pdf. Accessed 5 Dec 2019.

4. Bassuk EL, DeCandia CJ, Anne Beach C, Berman F. America's youngest outcasts: a report card on child homelessness. Waltham: The National Center on Family Homelessness; 2014. https://www.air.org/sites/default/files/ downloads/report/Americas-Youngest-Outcasts-Child-Homelessness-Nov2 014.pdf. Accessed 5 Dec 2019.

5. Crane M, Warnes AM. Homelessness among older people and service responses. Rev Clin Gerontol. 2010;20:354-63.

6. Grant R, Gracy D, Goldsmith G, Shapiro A, Redlener IE. Twenty-five years of child and family homelessness: where are we now? Am J Public Health. 2013:103(Suppl 2):e1-10.

7. Raising the Roof. Our Research. Raising the Roof. 2016. https://www.ra isingtheroof.org/resources/our-research/. Accessed 6 Dec 2019.

8. Helfrich CA, Aviles AM, Badiani C, Walens D, Sabol P. Life skill interventions with homeless youth, domestic violence victims and adults with mental illness. Occup Ther Heal Care. 2006;20:189-207.

9. Forchuk C, Richardson J, Laverty K, Bryant M, Rudnick A, Csiernik R, et al. Service preferences of homeless youth with mental illness: housing first, treatment first, or both together. In: Gaetz S, O'Grady B, Buccieri K, Karabanow J, Marsolais A, editors. Youth homelessness in Canada: implications for policy and practice. Toronto: Canadian Homelessness Research Network Press; 2013. p. 95-109.

10. Cobb-Clark DA, Zhu A. Childhood homelessness and adult employment: the role of education, incarceration, and welfare receipt. J Popul Econ. 2017;30: 893-924.

11. Kilmer RP, Cook JR, Crusto C, Strater KP, Haber MG. Understanding the ecology and development of children and families experiencing homelessness: implications for practice, supportive services, and policy. Am J Orthop. 2012;82:389-401.

12. Edidin JP, Ganim Z, Hunter SJ, Karnik NS. The mental and physical health of homeless youth: a literature review. Child Psychiatry Hum Dev. 2012;43:354-75.

13. Kulik DM, Gaetz S, Crowe C, Ford-Jones E. Homeless youth's overwhelming health burden: a review of the literature. Paediatr Child Health. 2011:16:e43-7.

14. Gultekin LE, Brush BL, Ginier E, Cordom A, Dowdell EB. Health risks and outcomes of homelessness in school-age children and youth: a scoping review of the literature. J Sch Nurs. 2019;36:10-8. 
15. Hodgson KJ, Shelton KH, Van Den Bree MBM, Los FJ. Psychopathology in young people experiencing homelessness: a systematic review. Am J Public Health. 2013;103:e24-37.

16. Haskett ME, Armstrong JM, Tisdale J. Developmental status and socialemotional functioning of young children experiencing homelessness. Early Child Educ J. 2016:44:119-25.

17. Cronley C, Jeong S, Davis JB, Madden E. Effects of homelessness and child maltreatment on the likelihood of engaging in property and violent crime during adulthood. J Hum Behav Soc Environ. 2015;25:192-203.

18. Stablein T, Appleton AA. A longitudinal examination of adolescent and young adult homeless experience, life course transitions, and health. Emerg Adulthood. 2013;1:305-13.

19. Kidd SA, Gaetz S, O'Grady B. The 2015 National Canadian Homeless Youth Survey: mental health and addiction findings. Can J Psychiatr. 2017;62:493-500.

20. Tsemberis S, Asmussen S. From streets to homes. Alcohol Treat Q. 1999;17: 113-31.

21. Tsemberis S. From streets to homes: an innovative approach to supported housing for homeless adults with psychiatric disabilities. J Commun Psychol. 1999;27:225-41.

22. Cnaan RA, Blankertz L, Messinger KW, Gardner JR. Psychosocial rehabilitation: toward a definition. Psychosoc Rehabil J. 1988;11:61-77.

23. Tsemberis S. Housing first: implementation, dissemination, and program fidelity. Am J Psychiatr Rehabil. 2013;16:235-9.

24. Bachrach LL. Psychosocial rehabilitation and psychiatry in the care of longterm patients. Am J Psychiatry. 1992;149:1455-63.

25. Tsemberis S, Gulcur L, Nakae M. Housing first, consumer choice, and harm reduction for homeless individuals with a dual diagnosis. Am J Public Health. 2004;94:651-6.

26. Government of Canada. Housing First. Government of Canada. 2019. https:// www.canada.ca/en/employment-social-development/programs/ homelessness/resources/housing-first.html. Accessed 6 Dec 2019.

27. Whittaker E, Swift W, Flatau P, Dobbins T, Schollar-Root O, Burns L. A place to call home: study protocol for a longitudinal, mixed methods evaluation of two housing first adaptations in Sydney, Australia. BMC Public Health. 2015;15:342

28. Greenwood RM, Stefancic A, Tsemberis S, Busch-Geertsema V. Implementations of housing first in Europe: successes and challenges in maintaining model fidelity. Am J Psychiatr Rehabil. 2013;16:290-312.

29. Aubry T, Nelson G, Tsemberis S. Housing first for people with severe mental illness who are homeless: a review of the research and findings from the at home_chez Soi demonstration project. Can J Psychiatr. 2015;60:467-74.

30. Woodhall-Melnik JR, Dunn JR. A systematic review of outcomes associated with participation in housing first programs. Hous Stud. 2016;31:287-304.

31. Boland L, Slade A, Yarwood R, Bannigan K. Determinants of tenancy sustainment following homelessness: a systematic review. Am J Public Health. 2018;108:e1-8.

32. Baxter AJ, Tweed EJ, Katikireddi SV, Thomson H. Effects of housing first approaches on health and well-being of adults who are homeless or at risk of homelessness: systematic review and meta-analysis of randomised controlled trials. J Epidemiol Commun Health. 2019;73:379-87.

33. Volk JS, Aubry T, Goering P, Adair CE, Distasio J, Jette J, et al. Tenants with additional needs: when housing first does not solve homelessness. J Ment Health. 2016;25:169-75.

34. Pearson C, Montgomery AE, Locke G. Housing stability among homeless individuals with serious mental illness participating in housing first programs. J Commun Psychol. 2009;37:404-17.

35. Collins SE, Malone DK, Clifasefi SL. Housing retention in single-site housing first for chronically homeless individuals with severe alcohol problems. Am J Public Health. 2013;103(Suppl 2):S269-74.

36. Malone DK. Assessing criminal history as a predictor of future housing success for homeless adults with behavioral health disorders. Psychiatr Serv. 2009:60:224-30

37. Byrne T, Henwood BF, Scriber B. Residential moves among housing first participants. J Behav Health Serv Res. 2018;45:124-32.

38. Adair CE, Streiner DL, Barnhart R, Kopp B, Veldhuizen S, Patterson M, et al. Outcome trajectories among homeless individuals with mental disorders in a multisite randomised controlled trial of housing first. Can J Psychiatr. 2017; 62:30-9.

39. Somers JM, Patterson ML, Moniruzzaman A, Currie L, Rezansoff SN, Palepu A, et al. Vancouver at home: pragmatic randomized trials investigating housing first for homeless and mentally ill adults. Trials. 2013;14:365.
40. Sheehan DV, Lecrubier Y, Sheehan KH, Amorim P, Janavs J, Weiller E, et al. The Mini-International Neuropsychiatric Interview (M.I.N.I.): the development and validation of a structured diagnostic psychiatric interview for DSM-IV and ICD-10. J Clin Psychiatr. 1998;59(Suppl 20):22-33.

41. Barker S, Barron N, McFarland BH, Bigelow DA. A community ability scale for chronically mentally ill consumers: part I. reliability and validity. Commun Ment Health J. 1994;30:363-83.

42. Tsemberis S, McHugo G, Williams V, Hanrahan P, Stefancic A. Measuring homelessness and residential stability: the residential time-line follow-back inventory. J Commun Psychol. 2007;35:29-42.

43. Somers JM, Moniruzzaman A, Patterson M, Currie L, Rezansoff SN, Palepu A, et al. A randomized trial examining housing first in congregate and scattered site formats. PLoS One. 2017:12:e0168745.

44. Dempsey D, Harrison LM. Sexual health service provision to the young and homeless. Youth Stud Aust. 1998:17:26-35.

45. United Nations. Youth. United Nations. [date unknown]. https://www.un. org/en/sections/issues-depth/youth-0/index.html. Accessed 31 Dec 2019.

46. Kozloff N, Adair CE, Palma Lazgare LI, Poremski D, Cheung AH, Sandu R, et al. "Housing first" for homeless youth with mental illness. Pediatrics. 2016; 138:e20161514.

47. Boothroyd RA, Chen HJ. The psychometric properties of the Colorado symptom index. Adm Policy Ment Heal Ment Heal Serv Res. 2008;35:370-8.

48. Marsden J, Gossop M, Stewart D, Best D, Farrell M, Lehmann P, et al. The Maudsley addiction profile (MAP): a brief instrument for assessing treatment outcome. Addiction. 1998:93:1857-67.

49. Dennis ML, Chan Y-F, Funk RR. Development and validation of the GAIN short screener (GSS) for internalizing, externalizing and substance use disorders and crime/violence problems among adolescents and adults. Am J Addict. 2006;15:80-91.

50. Patterson ML, Moniruzzaman A, Somers JM. History of foster care among homeless adults with mental illness in Vancouver, Bristish Columbia: a precursor to trajectories of risk. BMC Psychiatr. 2015;15:32.

51. Felitti VJ, Anda RF, Nordenberg D, Williamson DF, Spitz AM, Edwards V, et al Relationship of childhood abuse and household dysfunction to many of the leading causes of death in adults. The adverse childhood experiences (ACE) study. Am J Prev Med. 1998;14:245-58.

52. Hastie T, Tibshirani R, Wainwright M. Statistical learning with sparsity: the lasso and generalizations. Boca Raton: CRC Press; 2015.

53. Belloni A, Chernozhukov V, Hansen C. High-dimensional methods and inference on structural and treatment effects. J Econ Perspect. 2014;28:29-50.

54. Drukker D. Inference after lasso model selection. In: Proceedings of Stata Conference; 2019 Jul 11-12. Chicago: Stata Users Group; 2019. Available from: https://www.stata.com/meeting/chicago19/slides/chicago19_Drukker.pdf

55. Chernozhukov V, Chetverikov D, Demirer M, Duflo E, Hansen C, Newey W, et al. Double/debiased machine learning for treatment and structural parameters. Econ J. 2018;21:C1-68.

56. StataCorp. Stata Statistical Software (Release 16). College Station: StataCorp LLC; 2019.

57. Johnson G, Chamberlain C. From youth to adult homelessness. Aust J Soc Issues. 2008;43:563-82

58. Patterson ML, Currie L, Rezansoff S, Somers JM. Exiting homelessness: perceived changes, barriers, and facilitators among formerly homeless adults with mental disorders. Psychiatr Rehabil J. 2015;38:81-7.

59. Crystal S. Psychosocial rehabilitation and homeless youth. Psychosoc Rehabil J. 1986;10:15-21

60. Lee SJ, Liang $\sqcup$, Rotheram-Borus MJ, Milburn NG. Resiliency and survival skills among newly homeless adolescents: implications for future interventions. Vulnerable Child Youth Stud. 2011;6:301-8.

61. Gaetz S. THIS is housing first for youth: a program model guide. Toronto: Canadian Observatory on Homelessness Press; 2017. https://www. homelesshub.ca/HF4Y. Accessed 6 Jan 2020.

62. Gaetz S. Can housing first work for youth? Eur J Home. 2014;8:159-75.

63. National Academies of Sciences, Engineering, Medicine. Permanent supportive housing: evaluating the evidence for improving health outcomes among people experiencing chronic homelessness. Washington: National Academies Press; 2018. https://www.nap.edu/catalog/25133/perma nent-supportive-housing-evaluating-the-evidence-for-improving-healthoutcomes. Accessed 6 Jan 2020.

64. Bassuk EL, DeCandia CJ, Tsertsvadze A, Richard MK. The effectiveness of housing interventions and housing and service interventions on ending family homelessness: a systematic review. Am J Orthop. 2014;84:457-74. 
65. Collins CC, Bai R, Crampton D, Fischer R, D'Andrea R, Dean K, et al. Implementing housing first with families and young adults: challenges and progress toward self-sufficiency. Child Youth Serv Rev. 2019;96:34-46.

66. Gubits D, Shinn M, Wood M, Brown SR, Dastrup SR, Bell SH. What interventions work best for families who experience homelessness? Impact estimates from the family options study. J Policy Anal Manag. 2018;37:835-66.

67. Gaetz S, Schwan K, Redman M, French D, Dej E. The roadmap for the prevention of youth homelessness. Toronto: Canadian Observatory on Homelessness Press; 2018. https://www.homelesshub.ca/sites/default/files/ YPRfullreport_2.pdf. Accessed 9 Jan 2021.

68. Gaetz S, Dej E. A new direction: a framework for homelessness prevention Toronto: Canadian Observatory on Homelessness Press; 2017. https://www. homelesshub.ca/sites/default/files/attachments/COHPreventionFra mework_1.pdf. Accessed 9 Jan 2021.

69. Somers JM, Moniruzzaman A, Currie L, Rezansoff SN, Russolillo A, Parpouchi M. Accuracy of reported service use in a cohort of people who are chronically homeless and seriously mentally ill. BMC Psychiatr. 2016;16:41.

\section{Publisher's Note}

Springer Nature remains neutral with regard to jurisdictional claims in published maps and institutional affiliations.

Ready to submit your research? Choose BMC and benefit from:

- fast, convenient online submission

- thorough peer review by experienced researchers in your field

- rapid publication on acceptance

- support for research data, including large and complex data types

- gold Open Access which fosters wider collaboration and increased citations

- maximum visibility for your research: over $100 \mathrm{M}$ website views per year

At BMC, research is always in progress.

Learn more biomedcentral.com/submissions 